\title{
Aspectos da natureza da ciência na sala de aula: o caso da natureza da luz nos séculos XVII e XVIII
}

\section{RESUMO}

Boniek Venceslau da Cruz Silva boniek@ufpi.edu.br

$000-0002-1648-2652$

Universidade Federal do Piauí, Teresina Piauí, Brasil.
Neste trabalho, iremos apresentar um recorte da História da Óptica com o intuito de discutir as suas contribuições para o entendimento do processo de construção e derrocada de teorias científicas. Nele, realizamos um estudo histórico sobre as controvérsias existentes sobre a natureza da luz, nos séculos XVII e XVIII, no cenário inglês, como pano de fundo para discussões relacionadas à natureza do conhecimento científico. Vários estudos mostram que os futuros professores de ciências e os alunos da educação básica apresentam uma concepção de ciência não adequada. Nessa perspectiva, defendemos que o estudo de episódios históricos e a problematização de suas correlações com aspectos da Natureza da Ciência podem favorecer a construção de uma concepção de Ciência mais adequada nos futuros professores de Ciência. Por fim, sugerimos que estudos desta natureza podem contribuir para uma formação mais crítica do futuro professor de Ciências em questões relacionadas à natureza do conhecimento científico.

PALAVRAS-CHAVE: Ensino de Física. História e Filosofia da Ciência. Natureza da Ciência. Natureza da Luz. 


\section{Introdução}

A História da Ciência vem sendo objeto de estudo de várias pesquisas, sejam elas com finalidades historiográficas e (ou) educacionais. No que diz respeito a segunda vertente, uma quantidade significativa de trabalhos pretendem usar a História da Ciência (HC) como referencial capaz de subsidiar discussões sobre a Natureza da Ciência (veja, por exemplo: MOREIRA; MASSONI; OSTERMANN, 2007, OKI; MORADILLO, 2008; MOURA, 2008) e elaboração de estratégias didáticas (veja, por exemplo: FORATO, 2009; SOUZA, 2008; SILVA; MARTINS, 2010; SILVA, 2010; SILVA, 2011a).

Embora a inserção da HC seja quase consensual entre educadores, filósofos da ciência, historiadores da ciência e pesquisadores em ensino de ciências, um dilema ainda reside nas discussões dos pesquisadores da área: como podemos utilizar a HC na sala de aula? (FORATO, 2009; SILVA, 2010a).

Hoje, não é uma tarefa tão complexa encontrar discussões relacionadas à HC em livros didáticos e na internet. No segundo caso, com uma simples pesquisa ao termo História da Ciência, no Google (ferramenta padrão de pesquisa), podemos encontrar 685.000 possíveis fontes de consulta.

O problema encontra-se na fidedignidade e confiabilidade de algumas destas referências e desses sites. O maior problema reside quando os professores adotam e usam estes tipos de referências em suas aulas de Ciências.

Atualmente, no que diz respeito a HC, não é difícil encontrar uma infinidade de autores e trabalhos sobre a temática. Talvez, este fato ocorra devido à própria natureza do tema, o qual fascina cientistas e não cientistas. A celeuma reside, justamente, na qualidade dos episódios históricos produzidos.

Nesse ponto, Martins (2001) enfatiza que é possível encontrar uma infinidade de autores, das mais variadas formações, escrevendo na área de História da Ciência. Para o autor, alguns destes episódios históricos refletem uma História da Ciência anacrônica, distorcida e recheada de imprecisões historiográficas e conceituais. Ainda, para ele, esse fato pode ser explicado pela falta de competência técnica ao descrever o episódio histórico.

Nesse sentido, segundo Silva (2011b), é comum encontrarmos, tanto em sites da internet como em livros didáticos, erros ligados à História da Ciência e, em especial, à História da Óptica, como, por exemplo, dotar o modelo vibracional da luz de Huygens de características ondulatórias (comprimento de onda e amplitude) e definir Thomas Young como "descobridor" da difração da luz.

Dessa forma, além de se apresentar uma História da Ciência sem nenhum compromisso histórico ou conceitual, estes episódios históricos mal construídos contribuem para a construção de uma concepção de ciência inadequada dos professores que, possivelmente, farão uso deles. 
Contudo, cabe-nos indagar: qual é o papel do historiador da ciência e do educador na inserção da HC em sala de aula?

Acreditamos que é de responsabilidade do historiador da ciência analisar a Ciência na sua dimensão histórica, investigando suas transformações científicas no decurso do tempo; sendo sua tarefa selecioná-la, organizá-la e descrevê-la da forma mais fiel possível.

Já para o caso do professor, entendemos que ele deve ser capaz de reconhecer se o episódio histórico é de boa qualidade. Este fato remete, diretamente, na qualidade da sua formação inicial. Neste sentido, argumentamos que a sua formação inicial possibilite condições, mesmo que ainda minimizadas, de reconhecer a qualidade do episódio histórico selecionado.

Dessa forma, entendemos que são importantes discussões relacionadas ao uso adequado da HC na sala de aula e também uma fundamentação sobre aspectos epistemológicos da Ciência, os quais podem contribuir na seleção dos episódios históricos.

Portanto, a questão que fundamenta este trabalho é: como oportunizar esses momentos de discussões com os futuros professores de Ciências, ainda na sua formação inicial?

Neste trabalho, apresentamos um ensaio, o qual apresenta algumas das controvérsias existentes sobre a natureza da luz, principalmente nos séculos XVII e XVIII, no cenário da Inglaterra. Pretendemos, a partir do estudo desse ensaio, apresentar possibilidades de correlações entre o episódio histórico e aspectos da $\mathrm{NdC}$ inerentes ao episódio histórico.

Dessa maneira, entendemos que a discussão da NdC, a partir de episódios históricos, pode contribuir na formação científica de futuros professores de Ciências de forma menos dogmática e mais contextualizada com aspectos da Epistemologia da Ciência mais atualizados.

\section{A Natureza da Luz nos Séculos XVII e XVIII}

A luz sempre foi objeto de admiração no decorrer da história da humanidade. Por exemplo, na Grécia Antiga, as principais questões, sobre o assunto, direcionavam-se no sentido de elaborar explicações do como enxergamos um objeto. Neste período, várias explicações possuíram fundamentações de natureza míticas, filosóficas e religiosas na tentativa de explicar o que seria a luz.

Somente em meados do século XVII, muito influenciado por movimentos como o Renascimento, Iluminismo e a Revolução Científica, os estudos sobre a luz começam a perder sua natureza filosófica e passaram a exibir uma face científica, fundamentada na tríade previsão-experimentação-matematização dos fenômenos da natureza.

O século XVII ficou fortemente marcado pela Revolução Científica, ligada ao advento da mecânica newtoniana (unificadora da Física com a Astronomia) e da 
Ciência Moderna. Embora estivesse ligada a temas científicos, essa revolução retratou também mudanças na visão de mundo e na organização da sociedade.

Como afirma Rosa (2005), mesmo com a mudança de cenário, marcada pela Revolução Científica, algumas concepções metafísicas, baseadas na filosofia escolástica, ainda serviam como fundamentação para algumas novas teorias. Para o autor, esse fato mostrou uma mistura de prudência, interesse, medo, ou simplesmente clara conotação religiosa.

Foi nesse cenário que a Óptica, por volta do século XVII, apresenta dois modelos explicativos para a natureza da luz. O primeiro, com uma explicação de natureza corpuscular e, o segundo, com explicação vibracional-ondulatório.

O primeiro desses modelos foi associado ao nome de Isaac Newton, o qual sustentava que a luz era composta por minúsculas partículas (corpúsculos). Já o segundo modelo, é associado aos nomes de René Descartes, Christiaan Huygens, Robert Hooke e Thomas Young.

Descartes (1596-1650), um dos primeiros a caracterizar a natureza da luz como problema científico, sustentava que a luz tinha uma tendência natural ao movimento ou pressão e que ela era transmitida com velocidade infinita.

Em virtude de seu descontentamento com ideias precedentes acerca de experiências sobre a Óptica, o holandês Christiaan Huygens (1629-1695) reforça a hipótese vibracional-ondulatória, proposta anteriormente por Hooke, com a publicação, em 1678, do livro Tratado sobre a luz. Nessa obra, Huygens se posiciona contra o modelo corpuscular, como se verifica na passagem a seguir:

[...] quando vemos um objeto luminoso, isso não poderia ocorrer pelo transporte de uma matéria que venha do objeto até nós, como uma flecha ou bala que atravessa o ar (HUYGENS, 1986, p.12).

Valendo-se de analogias com o som, ele formula sua hipótese vibracional para a luz, conforme destacado no seguinte trecho contido no seu livro:

\begin{abstract}
Sabemos que, por meio do ar, que é um corpo invisível e impalpável, o som se propaga em toda a volta do lugar onde foi produzido, por um movimento que passa sucessivamente de uma parte do ar a outra. A propagação desse movimento se faz com igual velocidade para todos os lados e devem se formar como superfícies esféricas que crescem e que chegam a atingir nossas orelhas. Ora, não há dúvida de que a luz também não venha do corpo luminoso até nós por algum movimento impresso à matéria que está entre os dois, pois já vimos que isso não pode ocorrer pelo transporte de um corpo que passe de um até o outro. (HUYGENS, 1986, p. 12).
\end{abstract}

Para Huygens, a luz deveria se propagar em forma análoga ao ar, como podemos notar nas suas próprias palavras. Para exemplificar essa afirmação, observemos uma ilustração retirada diretamente do livro do Huygens. 
Figura 1: Propagação da luz por meio de ondas concêntricas.

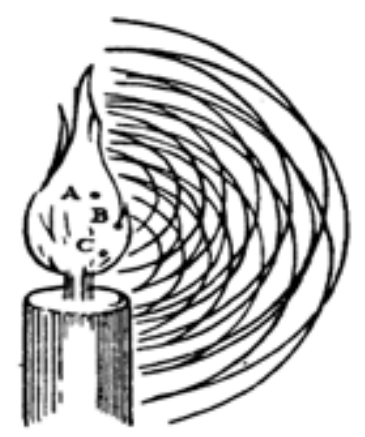

(Fonte: Tratado sobre a luz, HUYGENS (1986))

Já Robert Hooke (1635-1703), na sua obra Micrographia, afirmava que a luz seria gerada por vibrações em um meio, propagada por impulsos ou ondas simples de forma perpendicular.

Durante o século XVII, discussões relativas aos fenômenos como a reflexão, refração e sobre as cores agitariam o cenário da Óptica daquele tempo. É nesse período que Newton publicou seus primeiros trabalhos sobre Óptica, e, em especial, o seu trabalho A hipótese da luz, remetido por ele ao secretário da Royal Society, em 7 de dezembro de 1675.

Nesse trabalho podem-se verificar alguns apontamentos e, principalmente, algumas dúvidas suscitadas por Newton em relação à natureza da luz.

Para Cohen e Westfall (2002), os primeiros artigos de Newton (1642-1727) sobre Óptica são, provavelmente, inspirados no atomismo da época, representado pela figura de Pierre Gassendi (1592-1655). Nesse trabalho -A hipótese da luz-, Newton apresenta ideias corpusculares, mas não explicitamente, como veremos abaixo.

\footnotetext{
Fosse eu presumir uma hipótese, ela seria esta, se proposta em termos mais gerais, de modo a não determinar o que é a luz além de dizer que ela é uma ou outra coisa capaz de provocar vibrações no éter, pois, desse modo, ela se tornará tão geral e abrangente de outras hipóteses, que deixará pouco espaço para que outras sejam inventadas (COHEN; WESTFALL, 2002, p.31, grifo nosso).
}

Newton não deixa claro a sua postura diante da problemática. Esse fato é ampliado ao verificarmos a questão 29 da sua obra sobre a Óptica. Ele diz: os raios de luz não são corpos minúsculos emitidos pelas substâncias que brilham? (NEWTON, 2002, p.271).

Portanto, podemos observar que Newton não defendia abertamente a materialidade da luz.

No próximo tópico discutiremos mais um pouco sobre o livro de Newton sobre a Óptica, onde ele traz suas principais ideias sobre a luz. 


\section{O livro Óptica de Isaac Newton}

Já nos primeiros anos de seus estudos acadêmicos, Newton se preocupou em estudar assuntos relacionados à Mecânica, à Óptica, à Matemática e, também, à Teologia. Mas, é pela Óptica que Newton teria a sua primeira paixão e, igualmente, a sua grande primeira decepção.

Nos anos de 1670 e 1672, Newton foi nomeado professor lucasiano de Matemática da Universidade de Cambridge. Ele resolve, com apenas 27 anos, fazer aulas inaugurais sobre a teoria das cores e da refração. Essa exposição seria a mais abrangente feita por Newton sobre Óptica, servindo inclusive como base para a publicação do livro I do Óptica duas décadas depois (COHEN; WESTFALL, 2002).

Figura 2: Imagem da capa da edição do Óptica, em 1718.

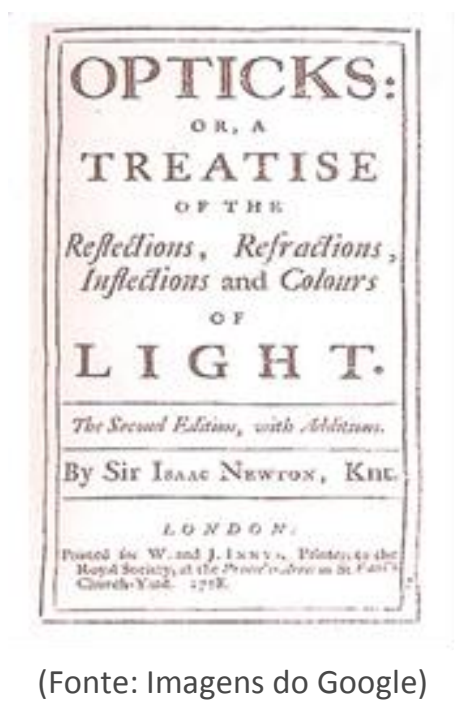

O seu livro viria a se tornar uma obra de grande influência para os estudos da Óptica desenvolvida no início do século XVIII na Inglaterra, pois, diferente do Principia (possuidor de uma linguagem matemática extremamente complexa), o Óptica era baseado em discussões de experimentos e proposições, o que o tornava uma leitura mais agradável e fácil de fazer, além de estar relacionado com a estrutura e a metodologia que Newton empregara no seu trabalho anterior, Principia.

No livro I do Óptica, Newton traz uma série de descrições muito bem elaboradas acerca de uma gama de experimentos, realizados por ele, para demonstrar as propriedades da luz discutidas no livro.

Nas primeiras linhas do livro I, Newton fala, com propriedade, do seu objetivo naquela obra: Meu objeto neste livro não é explicar as propriedades da luz por hipóteses, mas propô-las e prová-las pelo raciocínio e por experiências (NEWTON, 2002, p.39). 
Na sua obra Óptica, Newton traz várias questões por meio das quais ele apresenta argumentos em relação à natureza da luz. Para os seguidores da materialidade da luz, as questões formuladas por Newton seriam de grande importância para o desenvolvimento de seus modelos.

Como destacado, nesse artigo, o trabalho - A hipótese da luz - foi um dos primeiros relatos publicados por Newton sobre a luz. Nele, vemos a germinação do trabalho que se consolidou, posteriormente, no seu livro. Em ambas as obras, observamos a natureza especulativa dos seus trabalhos, principalmente nas noções de estados da luz, criadas para explicar os fenômenos luminosos estudados na época.

No livro II, Newton traz várias explicações para os estados da luz, observe:

Chamarei de fácil reflexão aos retornos da tendência de qualquer raio ser refletido; aos de sua tendência para ser transmitido, estados de fácil transmissão; e ao espaço que se sucede entre cada retorno seguinte, intervalo de seus estados (NEWTON, 2002, p.212).

Entretanto, o principal problema do conceito desenvolvido estava na origem dos estados da luz. Para Newton:

Todo raio de luz, em sua passagem através de qualquer superfície refratora, assume uma certa constituição ou estado transitório que ao longo da trajetória do raio retorna em intervalos iguais e faz com que em cada retorno o raio tenda a ser facilmente transmitido através da próxima superfície refratora e, entre os retornos, a ser facilmente transmitido por ela (NEWTON, 2002, p.210).

O motivo pelo qual as superfícies de todos os corpos espessos transparentes refletem parte da luz que sobre eles incide e refratam é que alguns raios, em sua incidência, estão em estados de fácil reflexão e outros em fácil transmissão (NEWTON, 2002, p.212).

[...] a luz se acha em estados de fácil reflexão e fácil transmissão antes de incidir sobre os corpos transparentes. E provavelmente ela assume esses estados na sua primeira emissão dos corpos luminosos e continua neles durante toda a sua trajetória (NEWTON, 2002, p.212-213).

Nas palavras de Newton: (a) é somente ao atravessar a superfície refratora que o raio passaria a apresentar os estados da luz e (b) os raios, ao serem incididos, seriam possuidores de tal propriedade.

Tal fato demonstra a possível dificuldade de Newton ao explicar os fenômenos luminosos, inclusive o que, futuramente, receberia o nome de anéis de Newton.

\section{Divergências e dificuldades nas explicações de fenômenos luminosos nos séculos XVII e XVIII.}

Nos séculos XVII e XVIII situar-se em torno de um ou outro modelo significava enxergar e entender a luz de formas diferentes. Portanto, esse fato implicou em 
explicações diferentes dos fenômenos luminosos, conhecidos hoje, da difração e interferência.

A difração, nos dias de hoje, é entendida como o desvio dado pela luz em relação a um obstáculo ou fenda. Ela foi descrita pelo estudioso jesuíta italiano Francesco Maria Grimaldi (1618-1663), que, na sua obra Physico-Mathesis de Lumine, Coloribus et Iride, publicada em 1665, descreve que a luz poderia possuir um fenômeno além dos conhecidos (reflexão, refração e difusão). Grimaldi chamou esse fenômeno de difração.

Segundo Bassalo (1987), Grimaldi teria descrito, em uma de suas experiências, que se um feixe de luz branca passasse através de dois estreitos orifícios, situado um atrás do outro, e em seguida atingisse um anteparo branco, haveria, nesse anteparo, uma região iluminada além da que deveria existir se a luz se propagasse em linha reta.

Ainda em 1665, Robert Hooke lançava o seu livro Micrographia. Esse trabalho é constituído por sessenta observações realizadas com um microscópio composto, que aumentava de 30 a 40 vezes a imagem. Hooke descreve experiências que mostram a presença de luz na sombra de um objeto iluminado, além de cores produzidas por uma lâmina transparente e fina de faces paralelas iluminadas com luz branca.

Figura 3: Desenhos representativos do microscópico desenvolvido por Robert Hooke.

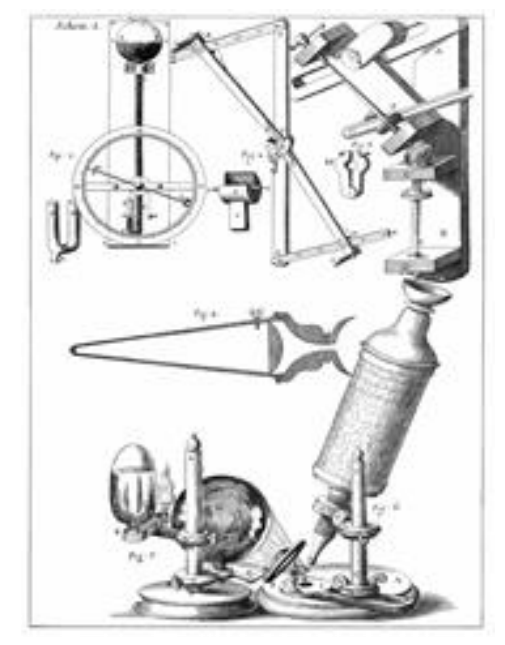

(Fonte: Micrographia, HOOKE (1665))

Nessa obra, Hooke também colabora no desenvolvido da atual Biologia, pois ele apresenta as suas observações feitas de plantas e animais. 
Figura 4: Inseto observado e desenhado por Hooke.

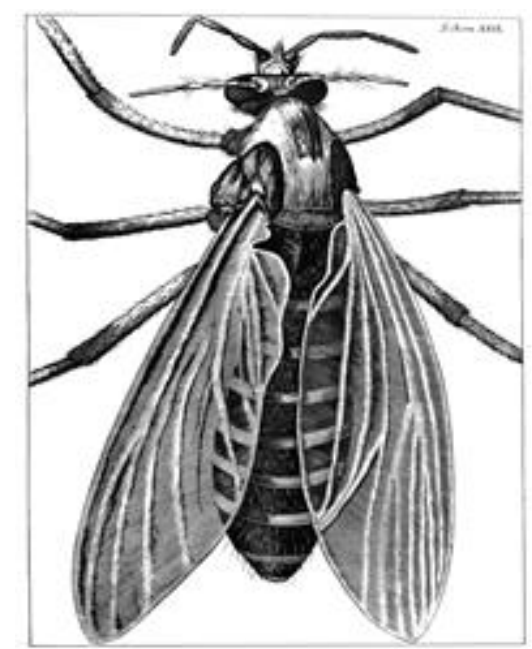

(Fonte: Micrographia, HOOKE (1665))

Diferente de Grimaldi, que se valeu do nome difração para explicar o fenômeno, Hooke utilizou o nome inflexão, provavelmente inspirando Newton, que estudou amplamente o Micrographia de Hooke, a utilizar no seu livro -Ópticao mesmo nome.

Newton mostrou um grande interesse sobre os resultados experimentais de Grimaldi (COHEN; WESTFALL, 2002). No livro III do Óptica, ele descreve:

\begin{abstract}
Grimaldi nos mostrou que se deixarmos um feixe de luz do sol entrar em um quarto escuro através de um orifício minúsculo, as sombras das coisas nessa luz serão maiores do que o seriam se os raios passassem pelos corpos em linhas retas e que estas sombras têm três franjas, faixas ou fileiras paralelas de luz colorida adjacentes a elas. Mas se o orifício for alargado, as franjas se alargarão e se encontrarão umas com as outras, de modo que não será possível distingui-las. Essas sombras e franjas largas têm sido consideradas por alguns como sendo decorrentes da refração ordinária do ar, mas sem o exame adequado do assunto (NEWTON, 2002, p.235).
\end{abstract}

Newton, provavelmente, é iniciado ao fenômeno da difração em 1672. Nesse mesmo ano, ele publicou seu primeiro artigo sobre Óptica. Seus primeiros comentários sobre a difração podem ser encontrados no artigo de 1675, chamado Hipótese da Luz.

Nele, Newton menciona Hooke e Grimaldi como os primeiros a tratar o tema da difração. Ele menciona Hooke e Grimaldi como os primeiros a tratar o tema da difração. A figura 5 mostra a descrição elaborada por Newton para a difração de Grimaldi: 


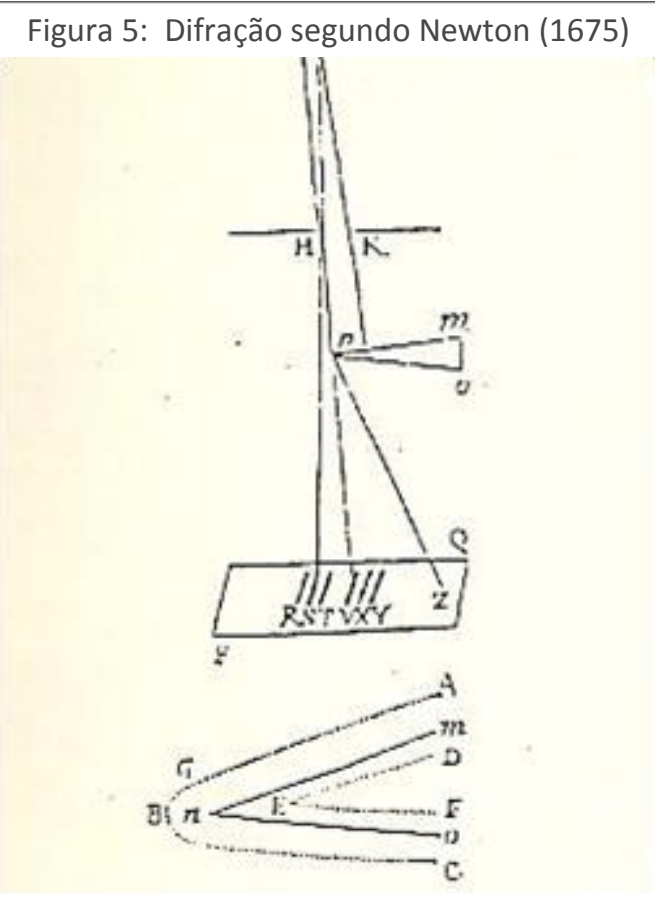

(Fonte: Óptica, NEWTON (2002))

Na descrição de Newton, a luz entra pelo orifício HK e chega até o papel PQ, onde ocorre a interceptação de parte dessa luz por um objeto mno, formando seis fileiras de cores RST e VXY. Nessa figura, é possível notar a diferença da sombra de um objeto que se propaga em linha reta.

A figura 6 representa a descrição feita por Newton de experimentos realizados por ele para estudar o fenômeno descoberto por Grimaldi. Os resultados desses experimentos foram enviados por carta a Boyle em fevereiro de 1679.

Na mencionada carta, ele explica que ABCD é um corpo opaco. Ele descreve o comportamento da luz que passa perto da borda de $A B C D$. Para ele, a experiência demonstra que a luz se curva em direção a $T$, mostrando que ela vai para dentro da sombra.

Figura 6: Difração descrita por Newton (1679).

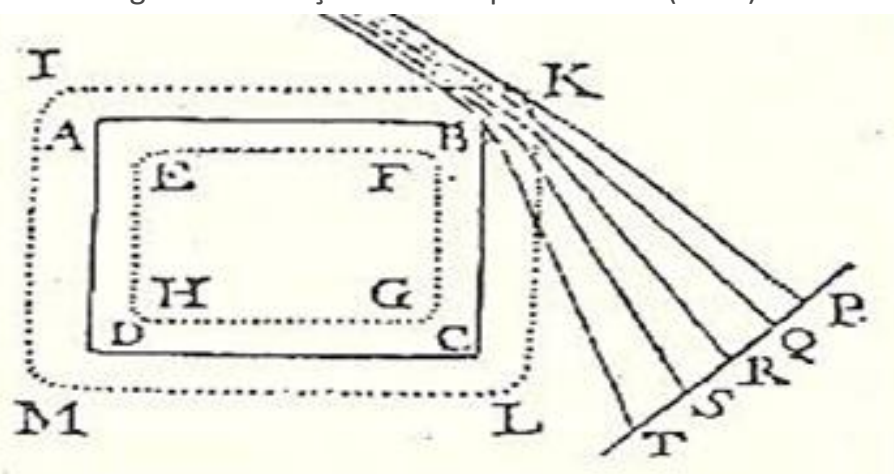

(Fonte: Óptica, NEWTON (2002)) 
Newton tentava explicar a inflexão (difração) com base em forças mútuas entre os corpúsculos, como as que, para ele, também agiriam na reflexão e na refração.

No trabalho de 1665, Grimaldi já tinha observado a presença de franjas coloridas internas e externas à sombra. Newton discute apenas as franjas externas.

Também muito controversa em relação à sua definição, a interferência suscitava, intrinsecamente na sua explicação, escolhas de uma perspectiva corpuscular ou ondulatória. No fim do século XVIII e início do século XIX, explicar e imaginar uma partícula sofrendo interferência era algo muito complicado para a ciência óptica.

Surgia, com esse fenômeno, um grande alerta aos postulantes e defensores do modelo corpuscular de Newton. Do lado contrário, os principais entraves relacionados aos modelos ondulatórias residiam na determinação experimental do comprimento de onda, além da própria fundamentação matemática que ela não possuía de forma coesa e sólida.

No século XVII, em particular, muitos dos físicos mais ilustres mostraram interesse e um profundo encantamento por esse fenômeno luminoso, como Robert Boyle (1627-1691), Robert Hooke e Isaac Newton.

No livro Experiments and considerations touching colours, publicado em 1664, Boyle examina o fenômeno. Para ele, as cores dos corpos não eram qualidades deles, mas eram produzidas por uma luz refratada ou refletida pelos corpos através de modificações da luz branca.

Hooke, por sua vez, no Micrographia, estuda profundamente o fenômeno. Ele realiza experimentos com o auxilio de microscópio, mostrado na figura 3 , em vários corpos, como a mica, superfícies de metais, dentre outros.

Newton já tinha estudado o Touching Coulour, de Robert Boyle, e o Micrographia, de Hooke. As suas primeiras experiências sobre a interferência são de 1666. Especialmente no seu ensaio Sobre as Cores, Newton começa a investigar o fenômeno, tomando como base uma concepção corpuscular para a luz.

As explicações de Newton sobre os anéis coloridos aparecem no Livro II do Óptica. Ele faz inúmeras descrições e observações acerca do fenômeno do aparecimento das cores. Para Newton, a luz possui predisposições para ser refletida ou refratada, conforme se percebe no trecho abaixo:

Todo raio de luz, em sua passagem através de qualquer superfície refratora, assume uma certa constituição ou estado transitório que ao longo da trajetória do raio retorna em intervalos iguais e faz com que em cada retorno tenda a ser facilmente transmitido através da próxima superfície refratora e, entre os retornos, a ser facilmente refletido por ela (NEWTON, p.210, 2002).

A explicação dada por Newton surge devido à necessidade desse fenômeno possuir dois raios para produzir os anéis de cores, como observado na figura 7. 
Figura 7: Anéis de cores numa película fina de ar entre a superfície de duas lentes.

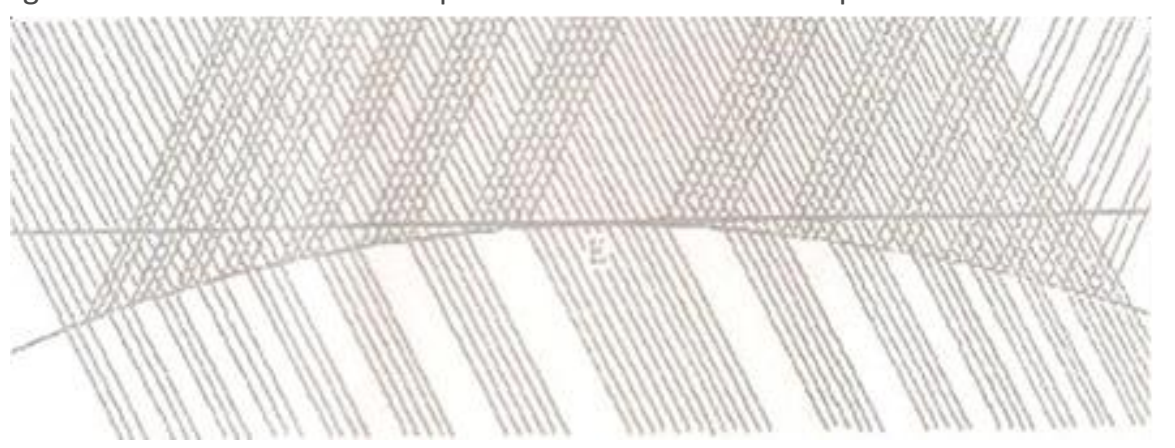

(Fonte: Óptica, NEWTON (2002))

Futuramente, Newton desenvolveria sua teoria dos estados de fácil transmissão e fácil reflexão para tentar explicar os anéis coloridos, tomando como base um modelo corpuscular para a luz.

Newton desenvolveu as noções de estados de fácil transmissão e fácil reflexão com a intenção de tentar explicar, primeiramente, os famosos anéis de Newton e expandir, posteriormente, a sua utilização à explicação de outros fenômenos ópticos, a exemplo da reflexão e da refração.

Um dos primeiros relatos do estudo de Newton, relacionado aos estados da luz, pode ser encontrado em um dos seus artigos, A hipótese da luz. Para Moura (2008), o caráter especulativo dessas discussões dificultou a sua aceitação e colocou uma dúvida em Newton em relação ao seu uso na Óptica.

Entretanto, as ideias de Newton e suas teorias continuaram ser aceitas, por algum tempo, devido não exclusivamente a sua ótima fundamentação teórica, como podermos observar nas discussões que seguem no corpo desse artigo.

\section{A influência newtoniana no século XVIII e a popularização da ciência}

O sucesso do Principia, publicado por Newton em 1687, obra na qual ele estabelece as leis para a mecânica, foi de grande relevância para que o seu segundo livro, o Óptica, fosse bem recebido pela comunidade acadêmica da época.

No Principia, Newton retrata a Óptica em algumas proposições. No ano da edição do Óptica, a mecânica newtoniana era bem famosa, certamente facilitando a aceitação desse seu segundo livro. Depois disso, tornou-se muito difícil não apoiar uma interpretação mecânica para a luz constituída por corpúsculos.

Dessa forma, seria uma missão complicada criticar o recém-criado modelo dinâmico da luz, baseado nas duas principais obras de Newton. Mas, como os modelos de natureza não material viriam a sobreviver a esses pressupostos? Esses modelos estariam fadados ao esquecimento?

Os modelos sobre a luz, de natureza corpuscular, formulados naquele período foram bem diferentes do que Newton viria a propor no seu livro. Eles constituíam modelos dinâmicos para a luz. Os seus seguidores acreditavam fortemente nas premissas contidas no Óptica e, com base nelas, formulavam seus próprios 
modelos baseados em pura especulação, fugindo da proposta idealizada por Newton (MOURA, 2008).

O que dever ser perguntado é: a supremacia de modelos ou concepções baseados nas ideias newtonianas ou o próprio modelo de explicação para a luz pensado por ele, durante aquele período, foram plenamente aceitos devido à sua melhor fundamentação teórica? Será que outros fatores viriam a influenciar a aceitação desses modelos? Os modelos de natureza corpuscular não sofreram indagações durante esse período?

Uma das características dos séculos XVII e XVIII foi o desejo de tornar o conhecimento adquirido pelo homem acessível à população. As ciências eram divulgadas por meio de aulas populares, nas quais eram realizadas demonstrações de experiências em praças públicas para a população mais leiga.

Será que durante as aulas populares, a imagem e a autoridade newtoniana colaboravam para que seu modelo corpuscular fosse privilegiado?

No fim do século XVII e início do século XVIII, as universidades ainda eram compostas por professores escolásticos e cartesianos, logo, modelos ondulatórios para a luz tinham adeptos, visto que os escolásticos, baseados em Aristóteles idealizador de um modelo vibracional para a luz -, seguiam os preceitos do tutor da Grécia.

Naquela época, a sociedade vivia um período de profundas mudanças, período esse marcado fortemente por Newton. A primeira edição do Principia foi dedicada ao patrono da Inglaterra, o rei James II. Foi nessa época que Newton foi eleito presidente da Royal Society.

Devido a sua influência, ocorreu uma gradativa substituição, nas principais universidades, de professores escolásticos e cartesianos por newtonianos ortodoxos, ocasionando aulas baseadas nas concepções de Newton.

Para Cohen e Westfall (2002), após Newton assumir a presidência da Royal Society em 1703, produzir o seu livro Óptica e trabalhar em conjunto com o filósofo John Theophilus Desaguliers (1683-1744), seria muito difícil contestar a doutrina newtoniana.

Naquele momento, esse fato foi encarado como uma grande conquista de Newton, sendo um registro a seu favor. No caminhar da história, esse acontecimento exigiria uma reconstrução sobre a controvérsia vivida na óptica daquela época.

Nas conferências desenvolvidas por John Teophilus Desaguliers, defensor ferrenho de Newton, era apresentada a filosofia natural newtoniana como uma verdade incontestável. Seus cursos eram repletos de demonstrações de fenômenos ópticos, que não necessitavam de conhecimento matemático para a sua explicação. A linguagem de fácil acesso mobilizava um grande número de observadores, desde a nobreza, passando pelo clero e chegando aos plebeus da Inglaterra (MOURA, 2008).

Entretanto, um fato curioso chama atenção, pois fenômenos como os anéis de Newton não eram abordados, muito possivelmente graças a seu alto grau de 
complexidade. Vale salientar que Newton não viria a formular um modelo robusto que viesse a explicar esse fenômeno.

Os experimentos que divergiam das explicações de Newton, por outro lado, eram descartados. Uma das explicações dada era que seus instrumentos estariam defeituosos (COHEN; WESTFALL, 2002). Atrelado a isso, era costumeiramente mostrado que o modelo vibracional não explicava os fenômenos ópticos de forma correta como o corpuscular assim o fazia. Parece que tudo levava para uma maior aceitação das concepções newtonianas.

Já a presença de algumas hipóteses relacionadas à natureza da luz eram baseadas nos argumentos de Newton encontrados no Óptica, especialmente nas questões do livro.

Outro fato marcante, que muito favoreceu a maior aceitação das convicções newtonianas, notadamente na Inglaterra e na França, foi a construção de uma imagem de herói nacional, postulada em Newton.

Segundo Moura (2008), era comum se encontrar nos palácios e nas repartições públicas da Inglaterra quadros e imagens de Newton. Atrelado a esse fato, a sua imagem era impressa em moedas e estátuas, fortalecendo ainda mais filosofia mecanicista newtoniana.

Mas, na segunda metade do século XVIII, os adeptos de modelos ondulatórios começavam a reiniciar estudos nessa perspectiva com destaque para Leonard Euler.

Em contrapartida a isso, os adeptos de uma materialidade para a luz deixam de lado alguns problemas encontrados na visão newtoniana e não discutiam, nas aulas populares, fenômenos que não pudessem ser contemplados pela teoria dinâmica da luz, por exemplo, os estados de fácil transmissão e fácil reflexão. Esses acontecimentos começaram a minar as convicções e as certezas que se tinha sobre os modelos corpusculares da luz.

Posteriormente, os estudos de Thomas Young (1773-1829) e Augustin Fresnel (1788-1827) colocariam em cheque o predomínio do modelo corpuscular da luz e das teorias dinâmicas para a luz desenvolvidas na primeira metade do século XVIII.

Nos próximos tópicos pretende-se discutir possibilidade de utilizar esse episódio histórico como ferramenta de discussões de aspectos da natureza da ciência em sala de aula.

\section{Aspectos da Natureza da Ciência e a controvérsia sobre a natureza da luz: o que podemos aprender com este episódio histórico?}

Hoje, a Natureza da Ciência ( $\mathrm{NdC}$ ), natural do termo inglês Nature of Science (NOS), é compreendida como conjunto de conhecimentos sobre a ciência que trata de seus limites, das influências com a sociedade da época, dos seus objetivos, das metodologias, da aceitação ou rejeição de ideias científicas, dos erros cometidos pelos cientistas ao tentar formular uma lei ou teoria e de outros tópicos (MOURA, 2008). 
Como destaca Matthews (1995), a ideia de ministrar aulas de ciências com base em tal perspectiva já estava presente no início do século XX. Essas posturas são diferentes de enfoques mais atuais e essa ideia de uma educação científica mais problemática e menos rígida já vem sendo discutida há algum tempo.

Para Adúriz-Bravo (2005), a imbricação da Natureza da Ciência com a história e a sociologia da ciência pode se agrupar em três grandes grupos temáticos, chamados de eixos da Natureza da Ciência, correspondendo a perguntas fundamentais que podem ser elaboradas sobre a ciência: (a) o eixo epistemológico, responsável por apontar o que é a ciência e como ela é elaborada; (b) o eixo histórico, responsável por mostrar como muda a ciência com o passar do tempo e (c) o eixo sociológico, responsável por caracterizar a relação da ciência com a sociedade e a cultura.

$\mathrm{Na}$ mesma linha destes trabalhos, outros tentam nos apresentar alguns aspectos da $\mathrm{NdC}$ ditos consensuais entre os pesquisadores da área, por exemplo: o objetivo principal da ciência é adquirir conhecimento científico do mundo natural; há no mundo uma ordem implícita que a Ciência procura descrever da maneira mais simples e compreensível; a ciência é dinâmica, mutável e experimental; não há nenhum método científico único (HARRES, 1999; EL-HANI, 2006; GIL et all, 2001; citando apenas alguns).

Lederman (1992), na sua revisão de textos que abordam tal assunto no ensino de ciências, identifica algumas linhas nessa temática, quais sejam: a investigação das concepções sobre a NdC apresentadas pelos estudantes e pelos professores, investigação de relações existentes entre a prática do docente e suas concepções sobre a $\mathrm{NdC}$ e a relação entre os currículos e a $\mathrm{NdC}$.

Especialmente, nesse trabalho, enfocaremos o desdobramento dessa primeira linha descrita por Lederman (1992). Esperamos utilizar o episódio histórico, como pano de fundo, para discutir para problematização concepções inadequadas que podem ser encontradas em futuros professores de Ciências.

Tal perspectiva é utilizada em trabalhos (veja, por exemplo: Moura (2008); Forato (2009) e Silva (2010a) que se vale de episódios históricos para a discussão de aspectos da $\mathrm{NdC}$.

No caso de Forato (2009) e Silva (2010a), além da apresentação e problematização de aspectos da $\mathrm{NdC}$, através de episódios históricos, os autores apresentam metodologias de inserção destas discussões em sala de aula, como, por exemplo, textos históricos, júri simulado e peças teatrais.

Neste trabalho, devido a limitações do tamanho do texto, escolhemos seguir a perspectiva de Moura (2008), o qual, no seu trabalho, apresenta o episódio histórico e correlações existentes entre ele e aspectos da $\mathrm{NdC}$.

Entendemos e defendemos que tais correlações podem propiciar ao professor formador possibilidades de construção e discussões de metodologias de ensino de aspectos da NdC de forma embasada.

A partir de agora, iremos apresentar correlações que podem ser feitas entre o episódio histórico e aspectos da NdC, conforme ressalta Lederman (1992).

1. As teorias são influenciadas por aspectos políticos, sociais e religiosos. 
No episódio histórico é possível notar que, principalmente na primeira metade do século XVIII, a autoridade newtoniana foi fundamental para divulgação da sua Óptica.

Por exemplo, a morte de Robert Hooke e a nomeação de Newton como presidente da Royal Society, cargo que viria a favorecer a popularização das suas ideias, foi determinante para a consolidação das ideias newtonianas.

Após um hiato de quase três décadas, Newton resolve publicar o seu livro sobre a óptica justamente após a morte dos seus opositores Huygens e Hooke. Com os atributos do cargo, Newton foi responsável pela demissão de professores aristotélicos, que utilizavam de argumentações de natureza divergente a sua. Assim, ele enfraqueceu, aos poucos, os estudos de natureza vibracional da luz na Inglaterra.

Outro fator importante foi a tentativa de construção de um heroi nacional inglês, o qual foi figurado na imagem do próprio Newton. Como destaca Moura (2008), não era incomum encontrar a imagem de Newton em órgãos públicos da Inglaterra, em moeda e estátuas da região.

Esta característica da Ciência (influencia de fatores políticos, sociais e religiosos) geralmente é descaracterizada dos livros de Ciência, os quais se preocupam, em alguns casos, apresentar os resultados da Ciência e não o seu processo. Quando apresentamos o processo de construção ou derrocada de teorias científicas esta característica é bastante recorrente.

Portanto, episódios históricos desta natureza são fundamentais para a apresentação e problematização desta característica da Ciência com os futuros professores.

2. A ciência é formada por interpretações ambíguas.

No episódio histórico é latente essa característica, encontramos uma forte divergência existente entre Newton e Huygens, Hooke e Descartes na explicação da natureza da luz e alguns de seus fenômenos.

Por exemplo, para Newton a luz era entendida como minúsculas partículas. Na contramão do ilustre pensador, Hooke entendia que a luz seria gerada por vibrações em um meio, propagada por impulsos ou ondas simples de forma perpendicular. Descartes afirmava que a luz tinha uma tendência natural ao movimento ou pressão e que ela era transmitida com velocidade infinita. Por fim, Huygens idealiza que a luz possuía uma natureza semelhante ao som.

A natureza ambígua das interpretações da Ciência, conforme destacam Silva, Carvalho e Nascimento (2014), é, geralmente, excluída dos livros didáticos, os quais tendem a apresentar somente a ideia, digamos de certa forma, vencedora de controvérsias, excluindo elas próprias do contexto de construção da teoria científica. É comum também, ainda segundo os autores, apresentar as interpretações ambíguas como "erros", descaracterizando o longo processo de suas construções ou derrocadas.

3. As teorias são formadas por hipóteses e não simplesmente por observações.

Newton formalizou, em alguns casos, hipóteses (estados da luz) encontradas principalmente no livro II do seu livro Óptica para explicar fenômenos ópticos. A 
principal ideia dele era utilizá-las para a explicação de fenômenos como a difração e a interferência.

4. Não existem deduções incontestáveis.

No episódio histórico podemos perceber que mesmo diante de toda blindagem, não exclusivamente de natureza teórica, as ideias de Newton sofrem contestações no século XVIII, em especial na sua segunda metade.

5. O conhecimento científico é dinâmico.

No decorrer da história da Óptica, sobretudo neste episódio, é observada a pluralidade de ideias, que coexistiram e fizeram alavancar os estudos sobre a luz, como, por exemplo, as recorrentes idas e vindas de modelos corpusculares e vibracionais-ondulatórios da luz, visando à explicação de fenômenos luminosos.

Esta outra característica é importante ser problematizada com os futuros professores. Segundo Silva, Carvalho e Nascimento (2014), alguns livros didáticos transmitem a noção da Ciência como algo estático e acabada, perpassando, inclusive, uma Ciência como produto acabado.

Acreditamos que esta noção pode colaborar com a aversão que a Ciência possui. Apresentar a Ciência como um produto inacabado e passível de mudanças, como o episódio histórico sustenta, pode também, possivelmente, atrair novos candidatos ao seu estudo.

Por fim, com o episódio histórico podemos observar que o processo de escolha de uma teoria científica é influenciado por vários fatores, por exemplo: (a) político, o cargo herdado por Newton de Presidente da Royal Society e sua influência com a nobreza facilitou a proliferação de suas ideias e a contestação de modelos científicos rivais e (b) social, a construção de uma imagem de heroi nacional britânico dificultava críticas às ideias propostas por Isaac Newton.

Outro elemento que vale ressaltar é que a ciência não é criada, pensada e formulada por uma única pessoa. Embora com toda a blindagem atrelada ao modelo corpuscular, idealizado inicialmente por Isaac Newton e reformulado por seus seguidores, ele foi objeto de discussão em seus pontos mais críticos. Este fato nos mostra que teorias científicas são temporais e não verdades últimas e estão sujeitas às contestações e críticas.

\section{Conclusões}

Atualmente para uma educação científica de qualidade é necessário que ela seja balizada em uma fundamentação adequada de conceitos científicos e em discussões de aspectos sobre a ciência (BRASIL, 2002).

Especificadamente sobre as discussões de aspectos sobre a ciência, as pesquisas mostram (veja, por exemplo: HARRES, (1999). TAIRAB (2001), ABD-ELKHALICK; LEDERMAN (2002), ABD-EL-KHALICK (2005)) que é uma necessidade que 
os professores possuam uma formação mais adequada sobre a ciência e o seu ensino.

As mesmas pesquisas apontam que, em alguns casos, a visão de ciência apresentada pelos professores é de natureza empírico-indutivista, influenciando, supostamente em suas aulas.

Nesse caso, supostamente devido as suas concepções de natureza empíricoindutivista, nota-se que alguns professores tentam apresentar as teorias científicas como o fruto exclusivo de observações de fatos e elaboração de experimentos cruciais responsáveis pela comprovação de teorias científicas, descaracterizando os fatores sociais, políticos e religiosos inerentes ao processo.

Este fato é corroborado por Silva (2010b), em um estudo exploratório com alunos ingressantes e concluintes da educação básica. O pesquisador aponta que os alunos da educação básica apresentam um alto grau de concepções sobre a Ciência de natureza empírico-indutivistas. Estas concepções convergem com as apresentadas por Lederman (1992) em relação aos professores de ciências, o que denota certo círculo vicioso.

Portanto, defendemos que a importância da inserção de aspectos da $\mathrm{NdC}$ em sala de aula, pois, conforme mostramos, neste trabalho, as correlações entre os episódios históricos e os aspectos da $\mathrm{NdC}$ podem colaborar na problematizar das concepções de ciências, quando inadequadas, de futuros professores de Ciências. 


\title{
Aspects of nature of science in the classroom: the case of the nature of light in the seventeenth and eighteenth centuries
}

\begin{abstract}
In this paper, we present an outline of the history of optics with the objective to discuss their contributions to the understanding of the construction process and collapse of scientific theories. We conducted a historical study of the controversies about the nature of light in the seventeenth and eighteenth centuries in the english context as a backdrop for discussions related about the nature of scientific knowledge. Several studies show that future science teachers and students of basic education have a conception of inadequate science. In this perspective, we argue that the study of historical episodes and the questioning of their correlations with aspects of Nature of Science may favor the construction of a better Science design in future science teachers. Finally, we suggest that such studies can contribute to a more critical training of future science teachers on issues related to the nature of scientific knowledge.
\end{abstract}

KEYWORDS: Physics Education. History and Philosophy of Science. Nature of Science. Nature of Light. 


\section{NOTAS}

\section{REFERÊNCIAS}

ABD-EL-KHALICK, Fouad. Developing deeper understandings of nature of science: The impact of a philosophy of science course on preservice science teachers' views and instructional planning. International Journal of Science Education, v. 27, n. 1, p. $15-42,2005$

ABD-EL-KHALICK, Fouad; LEDERMAN, Norman G. Improving science teachers' conceptions of nature of science: a critical review of the literature. International journal of science education, v. 22, n. 7, p. 665-701, 2000.

ADURIZ-BRAVO, Agustín. Una introducción a la naturaleza de la ciencia: La epistemología en la enseñanza de las ciencias naturales. Buenos Aires: Fondo de Cultura Económica, 2005.

Brasil. Ministério da Educação e Cultura. Parâmetros Curriculares Nacionais Ensino Médio. Brasília: 2002.

BASSALO, José Maria Filardo. A crônica da óptica clássica. Caderno Brasileiro de Ensino de Física, v. 4, n. 3, p. 140-150, 1987.

COHEN, I. Bernard; WESTFALL, Richard S. Newton: textos, antecedentes, comentários. Rio de Janeiro: EdUERJ/Contraponto, 2002.

EL-HANI, Charbel N. Notas sobre o ensino de história e filosofia da ciência na educação científica de nível superior. Estudos de história e filosofia das ciências: subsídios para aplicação no ensino. São Paulo: Editora Livraria da Física, p. 3-21, 2006.

FORATO, Thaís Cyrino de Mello. A Natureza da Ciência como saber escolar: um estudo de caso à partir da história da luz. 2009. Tese de Doutorado. Universidade de São Paulo (USP). Faculdade de Educação.

PÉREZ, Daniel Gil et al. Para uma imagem não deformada do trabalho científico. Ciência \& Educação, v. 7, n. 2, p. 125-153, 2001.

HARRES, João Batista Siqueira. Concepções de professores sobre a natureza da ciência. Porto Alegre, v. 284, p. 89-101, 1999. 
HUYGENS, Christiaan. Tratado sobre a luz. Cadernos de história e filosofia da ciencia. Supl., 1986.

LEDERMAN, Norman G. Students' and teachers' conceptions of the nature of science: A review of the research. Journal of research in science teaching, v. 29, n. 4, p. 331-359, 1992.

Nature of science: Past, present, and future. Handbook of research on science education, p. 831-879, 2007.

MARTINS, Roberto. de Andrade. História e História da Ciência: encontros e desencontros. In: Actas do 10 Congresso Luso-Brasileiro de História da Ciência e da Técnica. 2001. p. 11-45.

MATTHEWS, Michael. História, filosofia e ensino de ciências: a tendência atual de reaproximação. Caderno Brasileiro de Ensino de Física, v. 12, n. 3, p. 164-214, 2008.

MOREIRA, Marco Antonio.; MASSONI, Neusa.; OSTERMANN, Fernanda. História e Epistemologia da Física na Licenciatura em Física: uma disciplina que busca mudar as concepções dos alunos. Revista Brasileira de Ensino de Física, v.29, p.127-134, 2007.

MOURA, Breno A. A aceitação da óptica newtoniana no século XVIII: subsídios para discutir a natureza da ciência no ensino. 2008. Dissertação de mestrado, Instituto de Física, Universidade de São Paulo.

OKI, Maria da Conceição Marinho; DE MORADILLO, Edílson Fortuna. O ENSINO DE HISTÓRIA DA QUÍMICA: CONTRIBUINDO PARA A COMPREENSÃO DA NATUREZA DA CIÊNCIA. Ciência \& Educação, v. 14, n. 1, p. 67-88, 2008.

SILVA, Boniek Venceslau da Cruz. Controvérsias sobre a natureza da luz: uma aplicação didática. 2010a. Dissertação de mestrado. Programa de Pós-graduação em ensino de ciências e matemática, Universidade Federal do Rio Grande do Norte.

A Natureza da Ciência pelos alunos do ensino médio: um estudo exploratório. Latin-American Journal of Physics Education, v. 4, n. 3, p. 670-677, $2010 b$. 
História e Filosofia da Ciência como subsídio para elaborar Estratégias Didáticas em sala de aula: Um Relato de Experiência em sala de aula. Revista Ciências \& Ideias ISSN: 2176-1477, v. 3, n. 2, p. 1-14, 2011 a.

. O modelo vibracional da luz de Huygens e o ensino de Física: Equívocos, desafios e possibilidades. Latin-American Journal of Physics Education, v. 5, n. 2, p. 467-474, 2011.

SILVA, B. V. C.; MARTINS, A. F. P. A natureza da luz e o ensino da Óptica: uma experiência didática envolvendo o uso da História e da Filosofia da Ciência no ensino médio. Experiências em Ensino de Ciências, v. 5, n. 2, p. 71-91, 2010. SILVA, B. V. C.; CARVALHO, H. R.; NASCIMENTO, L. A. A História e Filosofia da Ciência em livros didáticos de ciências: o caso da História da Astronomia no Ensino Fundamental. In: XV Encontro de Pesquisa em Ensino de Física, 2014, Maresias - SP. Anais do XV EPEF, 2014. p. 1-9.

ROSA, Luiz Pinguelli. Tecnociências e humanidades: novos pardigmas, velhas questões, o determinismo newtoniano na visão de mundo moderna. Editora Paz e Terra, 2006.

SOUZA, José de Arimater de. Uma abordagem histórica para o ensino do princípio da inércia. 2008. Dissertação de mestrado. Programa de Pós-graduação em ensino de ciências e matemática, Universidade Federal do Rio Grande do Norte.

TAIRAB, Hassan H. How do pre-service and in-service science teachers view the nature of science and technology?. Research in Science \& Technological Education, v. 19, n. 2, p. 235-250, 2001. 
Recebido: 12 abri. 2015

Aprovado: 26 set. 2016.

DOI: http://dx.doi.org/10.3895/rbect.v9n2.1722

Como citar: SILVA, B. V. C. Aspectos da natureza da ciência na sala de aula: o caso da natureza da luz nos

séculos XVII e XVIII. Revista Brasileira de Ensino de Ciência e Tecnologia, v. 9, n. 2, 2016. Disponíve

em: <https://periodicos.utfpr.edu.br/rbect/article/view/1722>. Acesso em: xxx.

Correspondência:

Av Monteiro Lobato, 205, 84010-060 - Ponta Grossa - Paraná

Direito autoral: Este artigo está licenciado sob os termos da Licença Creative Commons-Atribuição 4.0

Internacional.

\section{(c) (1)}

